\title{
Impedance studies of polycrystalline tin oxide
}

\author{
James R. Currie · Ashok K. Batra • \\ Mohammad A. Alim · Manmohan D. Aggarwal · \\ Ravindra B. Lal
}

Published online: 24 April 2007

(C) Springer Science+Business Media, LLC 2007

\section{Erratum to: J Mater Sci: Mater Electron 18, 433-439 DOI 10.1007/s10854-006-9037-z}

In Figs. 4 and 5 the $y$-axis parameter printed is not correct although the curves therein represent the experimental data as mentioned in the paper. The corrected parameter for the $y$-axis for Figs. 4 and 5 is $1 / \omega \mathrm{C}_{\mathrm{s}}$ in Ohms.
The online version of the original article can be found at http:// dx.doi.org/10.1007/s10854-006-9037-z

\section{J. R. Currie}

Avionics Department, George C. Marshall Space Flight Center, Huntsville, AL 35812, USA

A. K. Batra · M. D. Aggarwal · R. B. Lal Department of Physics, Alabama A \& M University, P.O. Box 1268, Normal, AL 35762, USA

A. K. Batra

e-mail: ashok.batra@email.aamu.edu

M. A. Alim ( $\square)$

Department of Electrical Engineering, Alabama A \& M University, P.O. Box 297, Normal, AL 35762, USA

e-mail: mohammad.alim@aamu.edu

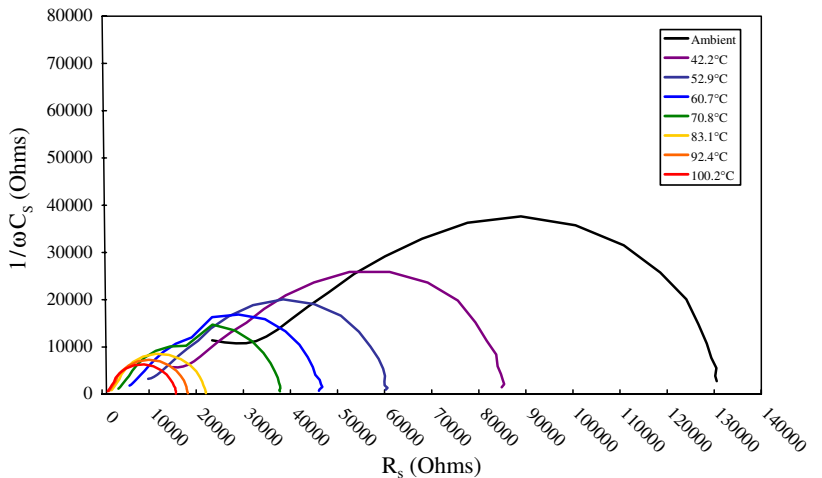

Fig. 4 Impedance plot at various temperatures of polycrystalline $\mathrm{SnO}_{2}$ without $\mathrm{He}$ implantation

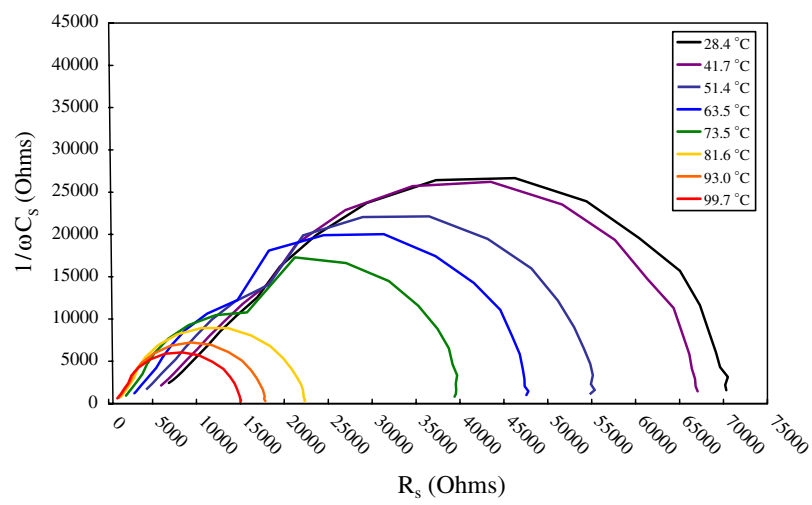

Fig. 5 Impedance plot at various temperatures of polycrystalline $\mathrm{SnO}_{2}$ with $\mathrm{He}$ implantation 